\title{
Effect of Hydrogen on the Fatigue Crack Propagation in Aluminum Alloys*
}

\author{
Akira KURUMADA ${ }^{1 *}$, Makoto SOUMA ${ }^{2}$, Takahito WATAKABE ${ }^{2}$ and Goroh ITOH $^{1}$ \\ ${ }^{1}$ Department of Mechanical Engineering, College of Engineering, Ibaraki University \\ 4-12-1 Nakanarusawa, Hitachi, Ibaraki 316-8511, Japan \\ ${ }^{2}$ Graduate Student, Graduate School of Science and Engineering, Ibaraki University, ditto. \\ *E-mail: kurumada@mx.ibaraki.ac.jp
}

\begin{abstract}
Keywords: Hydrogen Effect, Deuterium, Water Vapor, Aluminum Alloy, Fatigue Crack Propagation, Thermal Desorption Spectroscopy.
\end{abstract}

So far, 6061 aluminum alloy has been being used as a liner material of high-pressure hydrogen containers for fuel cell vehicles ${ }^{(1)}$, while higher-strength alloy is being demanded to increase the maximum fill pressure with a minimum increase in cost and weight. In this study, aluminum alloy plates of 6061 and 7075 both T6-tempered are subjected to fatigue test ${ }^{(2)}$ in air and heavy-water-vapor atmosphere at $303 \mathrm{~K}$ with relative humidity of $90 \%$ (HWA) ${ }^{(3)}$. Tests in the HWA are performed in order to distinguish environmental hydrogen that may invade the specimen from inherent hydrogen that has already been present in the specimen. The amount of deuterium in front of the crack tip is measured by means of thermal desorption spectroscopy, and the effect of hydrogen on the fatigue crack propagation is discussed based on the results obtained.

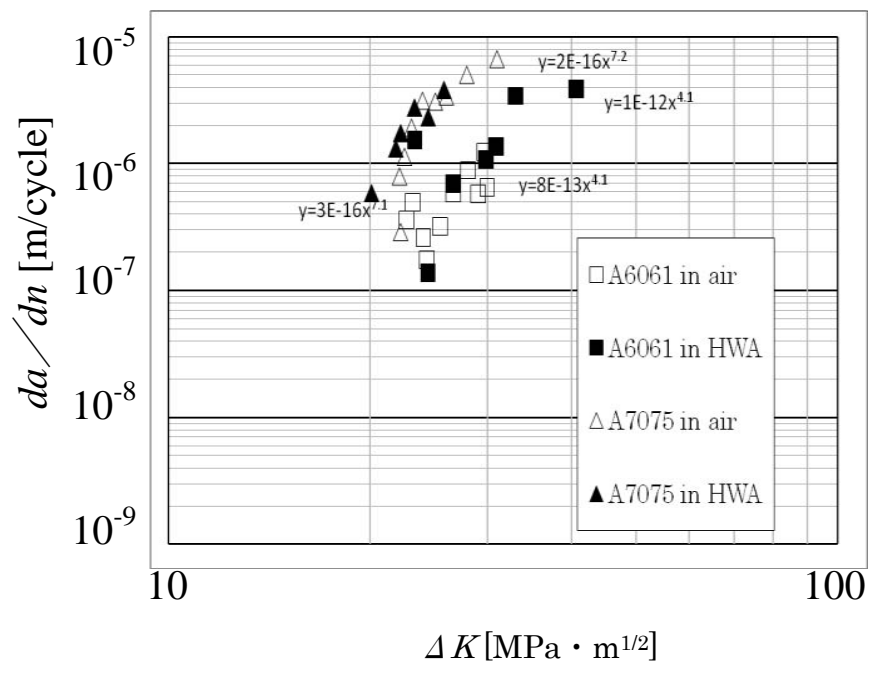

Fig. $1 d a / d n-\Delta K$ diagram.

The $d a / d N$ vs. $\Delta K$ plots in air and HWA are shown in Fig. 1 for the two aluminum alloys. From the results of fatigue tests in air, the exponents of clack propagation rate ${ }^{(4)}$ for A6061-T6 and A7075-T6 are 4.1 and 7.1, respectively, while those in HWA are 4.1 and 7.2, respectively. On the other hand, the amounts of deuterium in front of the crack tip in A6061-T6 and A7075-T6 show increases of 0.524 and $0.487 \mathrm{nA} \cdot \mathrm{K} / \mathrm{g}$ from the base materials, respectively.

6061 aluminum alloy is confirmed to have slower clack propagation rate than 7075 . The exponent in HWA for 6061 is equal to that in air in spite of the increase in the amount of deuterium by the crack propagation in HWA, while the exponent in the HWA for 7075 is slightly larger than that in air, corresponding with the increase in the amount of deuterium by the crack propagation in HWA. The effect of environmental hydrogen, therefore, is confirmed to a small extent in 7075 .

\section{References}

(1) S. Oosaki, J. Ikeda, M. Kinoshita and Y. Sasaki, J. Inst. Light Metals, Vol.56, No.12 (2006), pp.721-727.

(2) ASTM E647-83, (1983).

(3) G.A. Young Jr. and J.R. Scully, Metal. Mater. Trans., Vol.33A (2002), pp.101-115.

(4) Materials Science Society of Japan (H. Kobayashi), Materials and Fracture, ed. by Materials Science Society of Japan (M. Nakamura), Shokabo, (1989), p.33. 